LA W RENCE LIVERMORE N A TIONAL LABORATORY
Report on the Feasibility of $\mathrm{Pu}$ Photoelectron Spectroscopy with Microscopic and Nanoscopic Samples at NSLSII

J. G. Tobin

September 17, 2012 
This document was prepared as an account of work sponsored by an agency of the United States government. Neither the United States government nor Lawrence Livermore National Security, LLC, nor any of their employees makes any warranty, expressed or implied, or assumes any legal liability or responsibility for the accuracy, completeness, or usefulness of any information, apparatus, product, or process disclosed, or represents that its use would not infringe privately owned rights. Reference herein to any specific commercial product, process, or service by trade name, trademark, manufacturer, or otherwise does not necessarily constitute or imply its endorsement, recommendation, or favoring by the United States government or Lawrence Livermore National Security, LLC. The views and opinions of authors expressed herein do not necessarily state or reflect those of the United States government or Lawrence Livermore National Security, LLC, and shall not be used for advertising or product endorsement purposes.

This work performed under the auspices of the U.S. Department of Energy by Lawrence Livermore National Laboratory under Contract DE-AC52-07NA27344. 


\section{Report on the Feasibility of Pu Photoelectron Spectroscopy with Microscopic and Nanoscopic Samples at NSLSII}

\section{Proposition from Elio Vescovo}

However my personal goal from this meeting is to reach a firm conclusion on the possibility of doing micro-ARPES from thin film of Pu. I am only thinking that considering the light spot is so small (1 micron) and we can use thin films, it may be possible to have such a small amount of material in an ARPES experiment that it can be handled safely.

If this makes sense to you, I would like to ask you to estimate if a dotsample 1 micron in diameter and as ultrathin film of about $100 \mathrm{ML}$ thickness (I believe this less than nanograms) can be inserted in a vacuum chamber in direct open line with the synchrotron without jeopardizing the entire facility. i.e.: it must be that even in case that everything goes wrong and the material is evaporated on the walls of the vacuum chamber or entirely adsorbed in the vacuum pumps or all the other nasty things that can happen ... still the amount of radioactivity is so low of not posing a contamination problem. Unfortunately I do not know how to find it but I am convinced that there must be a lower limit on the amount of material below which there is no safety concerns. It is only if this lower limit is reached that I can see these type of experiments to become part of the current ARPES program.

\section{Analysis}

\section{Historical Context}

This is exactly what Dave Shuh does at the ALS, first on Beamline 7 [1] and now on Beamline 11. [2]

Beamline 7 excerpt [1]

III. NANOGRAM ACTINIDE PHOTOEMISSION

The first ultraESCA experiment to be performed at the SpectroMicroscopy Facility was a proof-of-principle demonstration of the analysis of a minute quantity of a radioactive transuranic sample. In this experiment approximately $1.25 \mu \mathrm{g}$ of the isotope curium-248 was deposited in the form of a curium oxide distributed uniformly over a spot $2.5 \mathrm{~mm}$ in diameter on a platinum disk. The total activity of the curium sample was less than 20 nanocuries, most of which arises from a trace curium-246 impurity in the curium-248 material. With a $50 \mu \mathrm{m}$ 


\section{Report on the Feasibility of Pu Photoelectron Spectroscopy with Microscopic and Nanoscopic Samples at NSLSII}

focused $x$-ray beam, only approximately 5 nanograms of curium-248 are estimated to be illuminated by the photon beam. The quantity of interest in future experiments will be matched to our focused spot size.

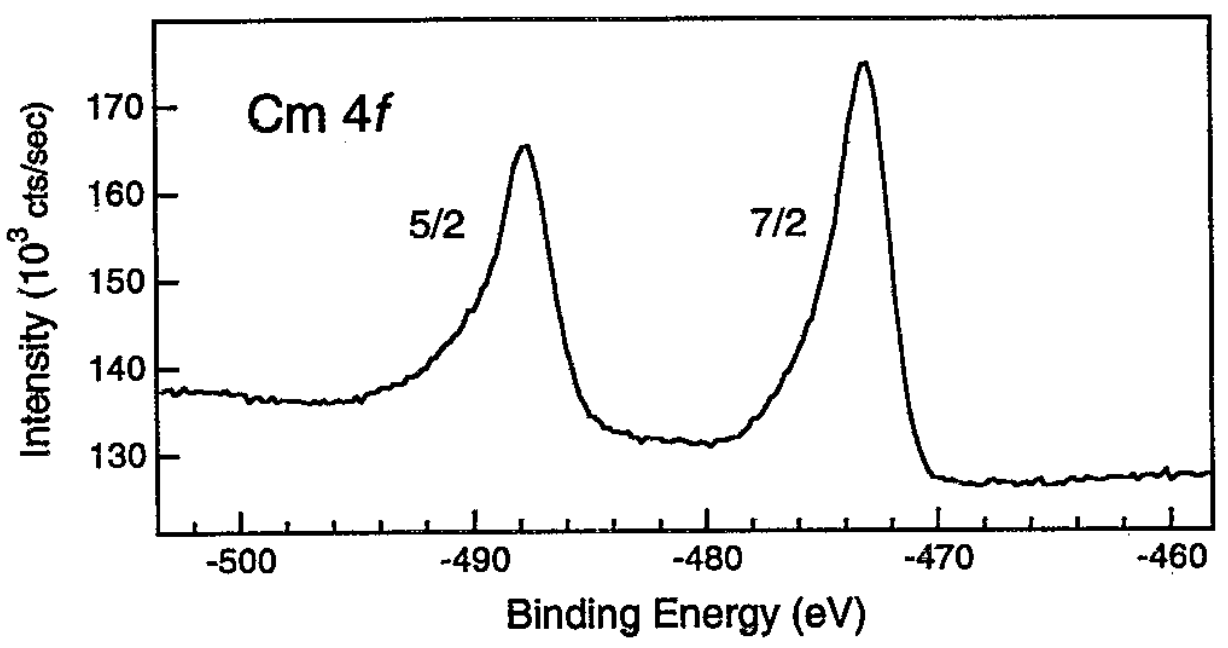

FIG. 3. Curium $4 f$ spectrum obtained with $h \nu=1040 \mathrm{eV}$ excitation. An estimated 3 nanograms of curium oxide was excited by the $\approx 50$ - $\mu \mathrm{m}$-diam beam spot.

\section{Figure 1: Figure 3 from Reference 1.}

Note that this is core level photoelectron spectroscopy, with no windows or containment inside the vacuum vessel.

Beamline 11 excerpt [2]

Soft X-ray STXM is potentially well suited for the investigation of actinide or other radioactive materials since the amount of material required is conservatively estimated to be on the order of $10 \mathrm{fg}$ for a particle. This simplifies safety considerations since the corresponding total activity would be well below a picocurie ( $p C i)$ if a single particle could be successfully isolated and mounted in the STXM sample holder for even the most radioactive of the common actinide nuclides. The radioactive material can be safely and permanently enclosed between two $50 \mathrm{~nm}$ thick silicon nitride windows to form a sample package suitable for STXM experiments. In practice, multiple particles are dispersed within the silicon nitride sample package. The overall safety envelope of the radioactive STXM experiments is further enhanced since the ALS-MES STXM end station is isolated from the ALS storage ring vacuum by a silicon nitride window, which permits the operation of the STXM under an ambient helium atmosphere, thereby avoiding problems that might arise from the exposure of the sample package to a vacuum. A prerequisite for STXM samples is that they have an accessible thickness of a few hundred nanometers depending on the 


\section{Report on the Feasibility of Pu Photoelectron Spectroscopy with Microscopic and Nanoscopic Samples at NSLSII}

elemental cross-section, energy of the absorption edge, and local elemental concentration.

This experiment is X-ray Absorption Spectroscopy, using silicon nitride windows and is less applicable to the NSLSII case.

\section{Radiation Levels versus mass}

To begin, let us define the problem. Radiological Facilities are those with amounts of radioactive material that stay under the Category 3 Threshold. Thus our discussion will be couched in terms of the Category 3 threshold.

\section{Excerpt from Reference 3.}

The heart of the matter is understanding that, in these large quantities, a substance is a mixture of more than one isotope. The fundamental mixture of (natural) uranium contains $234 \mathrm{U}, 235 \mathrm{U}$, and $238 \mathrm{U}$. To define the mixture it is necessary to know the exact process from which the material is derived. Depleted uranium from the gaseous diffusion process has a different isotopic composition from that produced in the AVLIS process. For a metal obtained from reactor fuel, the mixture may contain $236 \mathrm{U}$. Note that while these arguments are specific to uranium, the concept applies to any element which is a mixture of isotopes with which the analyst may be concerned. The weight per cent of each isotope in the mixture must be known if the appropriate limit is to be determined (see the computation for plutonium below). It is true that if the most abundant element has the highest specific activity, using its threshold limit will result in the most conservative estimate for the mixture. Otherwise the effect of all isotopes should be considered.

To calculate the Category 3 limit, the following equations are used. [3]

\section{SUBSTANCE/MIXTURE THRESHOLD CALCULATION:}

The final mass threshold value for the substance is found by using the sum of the ratios technique described in STD 1027-92 for "combinations of radioactive materials". The fundamental relationships for these calculations are:

$$
\begin{aligned}
& n=\sum_{i} \frac{q_{i} \times S A_{i}}{T_{i}} \text { and } \\
& q_{i}=f_{i} \times Q \\
& \text { where: } \\
& n=\text { the ratio of the individual isotope activity contribution in the mixture } \\
& \text { compared to the Category threshold value } \\
& n=1 \text { for the case where the inventory is at the mass threshold limit } \\
& q_{i}=\text { the mass of the isotope in the mixture }(\mathrm{g}) \\
& S A_{i}=\text { specific activity for isotope } \mathrm{i}(\mathrm{Ci} / \mathrm{g}) \\
& T_{i}=\text { the radioactivity threshold for isotope } \mathrm{i}(\mathrm{Ci}) \\
& f_{i}=\text { weight } \% \text { of the isotope in the mixture as a decimal fraction } \\
& Q=\text { mass of the mixture } \\
& \text { Therefore, when } \mathrm{n}=1, Q=\text { the mass threshold limit, and } \\
& \frac{1}{Q}=\sum_{i} \frac{f_{i} \times S A_{i}}{T_{i}}
\end{aligned}
$$

For a given substance the values for $T_{i}$ may not be listed in Table A.1 of STD 1027-92. 


\section{Report on the Feasibility of Pu Photoelectron Spectroscopy with Microscopic and Nanoscopic Samples at NSLSII}

The calculation for fuel grade Pu looks like this.[3]

Table 1. Determination of Mix Category 3 Mass Threshold Value-Pu Fuel Grade.

\begin{tabular}{|c|c|c|c|c|c|}
\hline Isotope & $\begin{array}{l}f_{i} \\
\text { (wt. } \% / 100\end{array}$ & $\begin{array}{l}\mathrm{SA}_{\mathrm{i}} \\
(\mathrm{Ci} / \mathrm{gm})\end{array}$ & $\mathrm{T}_{\mathrm{i}} \quad(\mathrm{Ci})$ & $\begin{array}{l}f_{i} \times S A_{i} \\
(\mathrm{C} i / g m)\end{array}$ & $\begin{array}{l}\left(f_{i} x_{i}\right)^{f E^{\prime} E_{i}} \\
(1 / g)\end{array}$ \\
\hline $23 \phi_{\mathrm{pu}}$ & 0.001 & 17.0 & 0.62 & 0.017 & 0.027 \\
\hline $239 \mathrm{Pu}$ & 0.78 & 0.062 & 0.52 & 0.048 & 0.092 \\
\hline $24 Q_{u}$ & 0.18 & 0.23 & 0.52 & 0.041 & 0.079 \\
\hline 24 Pu & 0.016 & 103.0 & 32.0 & 1.648 & 0.052 \\
\hline $24 \Phi_{\mathrm{u}}$ & 0.0049 & 0.004 & 0.62 & 0.000 & 0.0 \\
\hline $24 \mathrm{Am}$ & 0.019 & 3.47 & 0.52 & 0.066 & 0.127 \\
\hline \multicolumn{5}{|l|}{$\sum$} & 0.377 \\
\hline
\end{tabular}

Note that $\mathrm{Ti}$, the threshold limit, is isotope specific!

The calculation for weapons grade $\mathrm{Pu}$ is similar, with quantity of $5.67 \mathrm{~g}$. [3]

It would be useful to quantify the samples versus the Category 3 threshold. For the sake of simplicity, we will define the Category 3 threshold as $1 \mathrm{~g}$ of $\mathrm{Pu}$.

\section{Table 2}

Category $3 \quad 1 \mathrm{~g} \mathrm{Pu}$

$10^{-3} \mathrm{C} 3 \quad .001 \mathrm{~g} \mathrm{Pu}=1$ milligram $\mathrm{Pu}$

$10^{-6} \mathrm{C} 3 \quad .000001 \mathrm{~g} \mathrm{Pu}=1$ microgram $\mathrm{Pu}$

$10^{-9} \mathrm{C} 3 \quad .000000001 \mathrm{~g} \mathrm{Pu}=1$ nanogram Pu

ALS BL 7 PES [1] $1.25 \mu \mathrm{g}$

$10^{-12} \mathrm{C} 3 \quad .000000000001 \mathrm{~g} \mathrm{Pu}=1$ picogram Pu

ALS BL 7 PES [1] 3 ng

$10^{-15} \mathrm{C} 3 \quad .000000000000001 \mathrm{~g} \mathrm{Pu}=1$ femtogram Pu ALS BL 11 XAS [2] $10 \mathrm{fg}$

Next, it would be useful to calculate the mass of a disc of Pu. The disc will have a thickness $t$ and diameter $d$. The volume, $V$, of the disc would be as follows. $\mathrm{V}=\pi(\mathrm{d} / 2)^{2} \mathrm{t}$

The mass $(M)$ of the disc would be as shown below. $D$ is the density.

$\mathrm{M}=\mathrm{V} \times \mathrm{D}$

For $\mathrm{Pu}, \mathrm{D}=19.8 \mathrm{~g} / \mathrm{cm}^{3}$, from Ref 4 . The density of Pu can change by $25 \%$ between phases, but we will neglect that for now. [5]

For a TEM size disc, $\mathrm{t}=0.15 \mathrm{~mm}=.015 \mathrm{~cm}$ and $\mathrm{d}=3 \mathrm{~mm}=0.3 \mathrm{~cm}$. $V_{\text {TEM }}=(3.14159)(0.3 \mathrm{~cm} / 2)^{2}(0.015 \mathrm{~cm})=0.001 \mathrm{~cm}^{3}$ 
Report on the Feasibility of Pu Photoelectron Spectroscopy with Microscopic and Nanoscopic Samples at NSLSII

$M_{\text {TEM }}=0.001 \mathrm{~cm}^{3} \times 19.8 \mathrm{~g} / \mathrm{cm}^{3}=.02 \mathrm{~g}=20 \mathrm{mg}$.

This is roughly consistent with the masses of $30 \mathrm{mg}$ quoted in Reference 4.

For a sample such as that proposed by for the NSLSII, $t=100 \mathrm{ML} \approx 300$ angstroms $=30 \mathrm{~nm}=3 \times 10^{-6} \mathrm{~cm}$ and $\mathrm{d}=1$ micron $=1$ micrometer $=10^{-4} \mathrm{~cm}$.

$V_{\text {NSLS }}=(3.14159)\left(10^{-4} \mathrm{~cm} / 2\right)^{2}\left(3 \times 10^{-6} \mathrm{~cm}\right)=2.4 \times 10^{-14} \mathrm{~cm}^{3}$

$M_{\text {NSLS }}=2.4 \times 10^{-14} \mathrm{~cm}^{3} \times 19.8 \mathrm{~g} / \mathrm{cm}^{3}=5 \times 10^{-13} \mathrm{~g}=0.5 \mathrm{pg}$.

These values are much like those used in much like those used in Ref. $1 \& 2$.

So, as shown by Dave Shuh et al, this approach may be feasible in terms if radiation limits. The problem is sample preparation and surface quality.

\section{Sample Preparation and Surface Quality}

Elemental actinide surfaces have a lifetime on the scale of three hours. [5,6]

Preparation of actinide surfaces is difficult. Consider the excerpts from

Reference 6.

Illa Photoelectron spectroscopy requires a clean, well-defined surface.

\section{Hidden role of electrons: limiting sampling depth}

- While soft $x$-rays and

vacuum ultra-violet

radiation have limited

penetration and escape

depths, it is the mean free

paths of the electrons that

actually are the greatest limitation.

- Trelenberg et al, Surface Science 600, 2338 (2006)

- Bedrossian et al, MRS Symp. Proc. 437, 79 (1996): TEY MFP = 22A

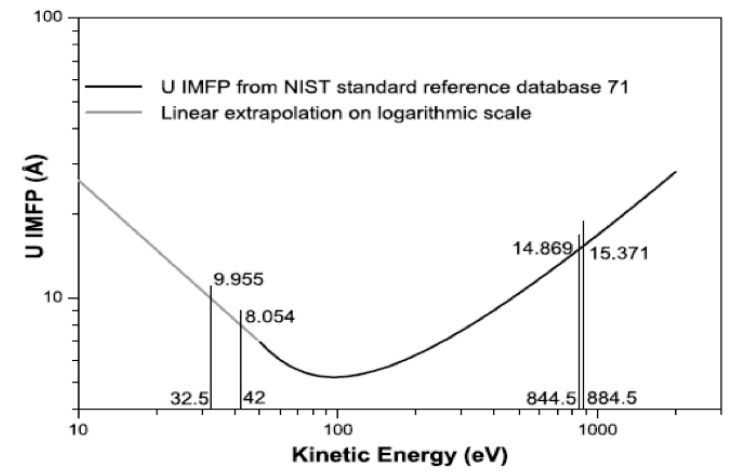

Fig. 7. Electron inelastic mean free path (IMFP) vs. kinetic energy for uranium. IMFP value values from $2000 \mathrm{eV}$ to $50 \mathrm{eV}$ taken from NIST database \#71 [26]; values less than $50 \mathrm{eV}$ were extrapolated from the database values.

If the measured $\mathrm{x}$-ray absorption signal arising from a depth $z$ in the specimen for a given white line energy is proportional to $I(z) \operatorname{Exp}(\cdot z / \mu)$, then the measured, relative intensities of the absorption edges of $\mathrm{Ni}, \mathrm{Fe}$, and $\mathrm{Co}$ in the spectra are consistent with $\mu=22 \AA$. The $\mathrm{Cu}$ spacer layer, which is buried under at least $13 \AA$ of $\mathrm{Co}$ and $50 \AA$ of Permalloy in each specimen, does not contribute appreciably to the absorption signal. Therefore, the MXCD measurement detects not the average magnetic response of different layers but rather the magnetic moment present in the outermost layer for each magnetic element.

Figure 2: Page 6 of Reference 6 
Report on the Feasibility of Pu Photoelectron Spectroscopy with Microscopic and Nanoscopic Samples at NSLSII

Illb Cleaving is a good way to get a clean surface, but ....

\section{Sample prep: cleaving crystals,} following the HTSC example

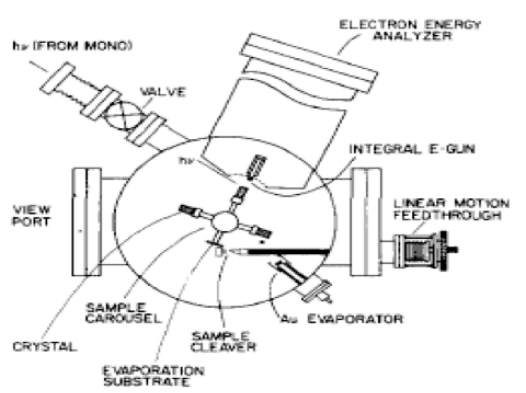

Spicer et al, Thin Solid Films 56, 1[1979]

- This is a very good way to make clean samples.

- The trick is to get a good cleavage plane.

- UWSRC experiments were often cleaved samples. [OIson \& LANL].

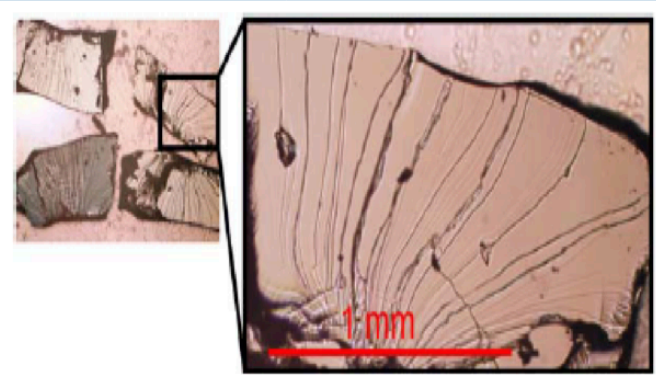

Barisic et al, SLAC-PUB-13412, Sept 2008

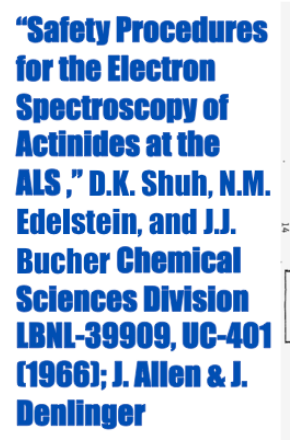

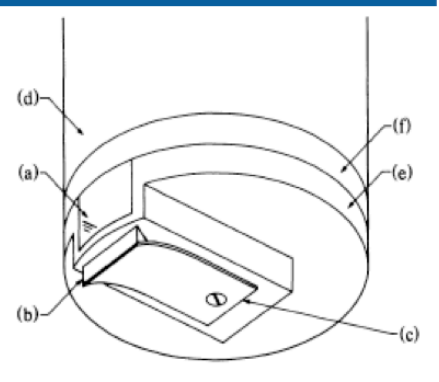

Hanemane \& Bachrach, PRB 27, 3927 [1983]

Figure 3: Page 7 of Reference 6

The microcrystal cleavers shown below are particularly good with actinide compounds. These compound samples are on the scale of $d=1 \mathrm{~mm}$ and $t=0.2$ $\mathrm{mm}$, so they are bigger than the proposed NSLSII samples. Moreover, metallic surfaces don't cleave well.

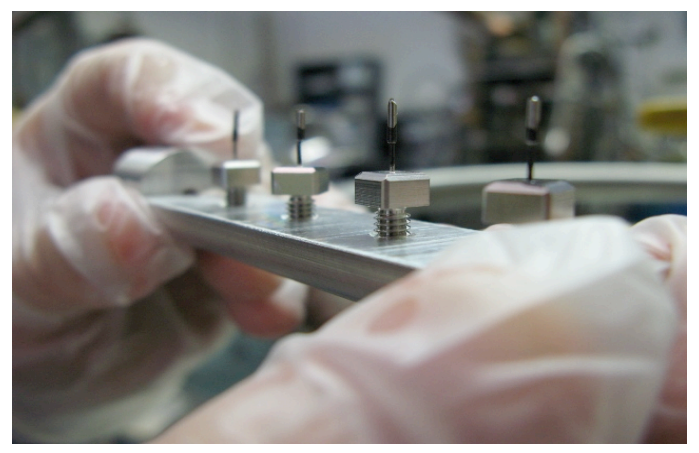

$\mathrm{Yb}_{0.24} \mathrm{Sn}_{0.76}$ Ru crystals for PES experiment Los Alamos, 2007 or 2008
Figure 4: $1 \mathrm{~mm}$ samples mounted on pin cleavers. Courtesy of $T$. Klipczuk, ITU, and T. Durakiewicz, LANL. 
Report on the Feasibility of Pu Photoelectron Spectroscopy with Microscopic and Nanoscopic Samples at NSLSII

IIlc Thin film deposition can also provide very clean surfaces but...

\section{Sample prep: thin film deposition, e.g. via plasmas}

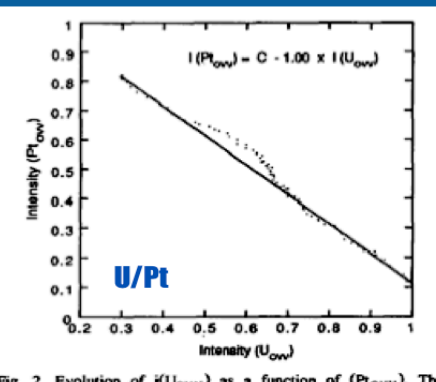

Fig. 2. Evolution of $\left(\mathrm{U}_{\text {ovv }}\right)$ as a function of $\left(\mathrm{P}_{\text {ovy }}\right)$. The

reference $\mathrm{U}_{\text {ovv }}$ spectrum has been normalized to get a slope of
-1 .

Gouder \& Comenares,

Surf. Sci.341, 51 [1995]

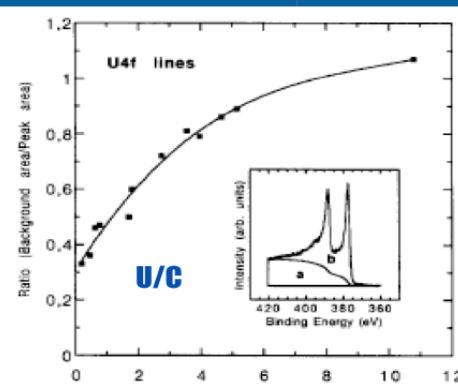

$\mathrm{U}$ Overlayer thickness (monolayers)

Gouder, Comenares \& Naegele, Surf. Sci. 342, 299 [1995]

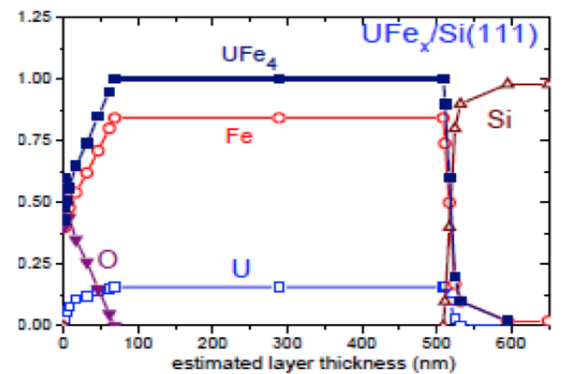

Adamska, Havela, Gouder et al

J. Phys. Conf Series 200, 012057 [2010]

- As with Rare Earths, vapor deposition is an excellent way to make clean actinide samples

- ITU has a long track record of vapor deposition using plasmas, including Pu and Am.

Figure 5: Page 8 of Reference 6.

Sample Prep: laser ablation at LLNL

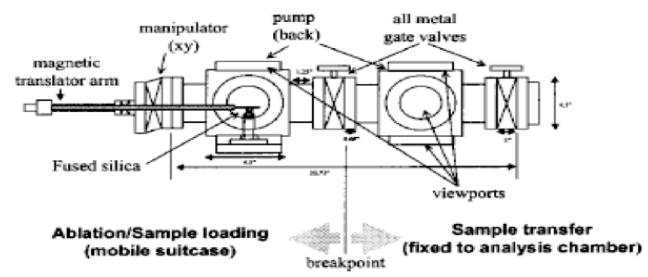

FIG. 3. Laser ablation/sample transfer schematic showing the mobile suitcase as well as the sample transfer chamber, which is attached to the main analysis chamber (not shown).

Trelenberg et al, Rev. Sci. Instrum. 75, 713 [2004] Trelenberg et al, Surface Science 600, 2338 [2006]

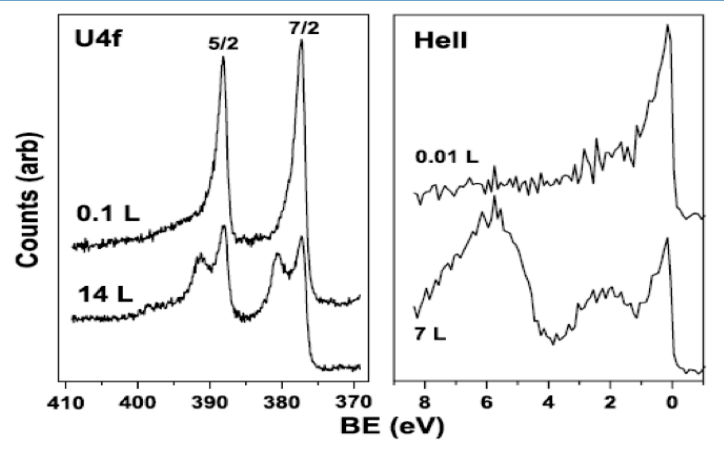

Fig. 1. Photoemission from both the U4f core level (Mg K $\alpha$ XPS) and the Fermi level (He II UPS) show an unoxidized uranium surface produced by laser ablation (upper scans). With exposure over time additional peaks are seen (U4f: $\sim 380$ and $391 \mathrm{eV}$; Fermi: $\sim 2$ and $6 \mathrm{eV}$ ).

- As a test for possibly depositing Pu, U nanoscale films were prepared in situ using laser ablation.

- The oxidation of the U films was also studied.

Figure 6: Page 9 of Reference 6. 


\section{Report on the Feasibility of Pu Photoelectron Spectroscopy with Microscopic and Nanoscopic Samples at NSLSII}

Vapor deposition can produce small, ultra-thin films, but the deposition chamber will have significant amounts of radioactive contaminants. Because the samples have only a lifetime of three hours, these need to be nearby. Direct transfer in vacuo is preferable, requiring the deposition be in the same room as the analysis. Sample transfer by vacuum suitcase is possible, but the poorer vacuum will shorten the lifetime further, [5] probably rendering the experiment impossible.

\section{Alignment Issues}

There is also the issue of sample alignment and the avoidance of spectral contamination. Unfortunately, our experience with a small $\mathrm{UO}_{2}$ sample indicates that there are often alignment problems associated with using a small sample and a small $\mathrm{x}$-ray spot. An example is shown below. [7] Note the poor signal to noise and the presence of the Co spectral contamination.

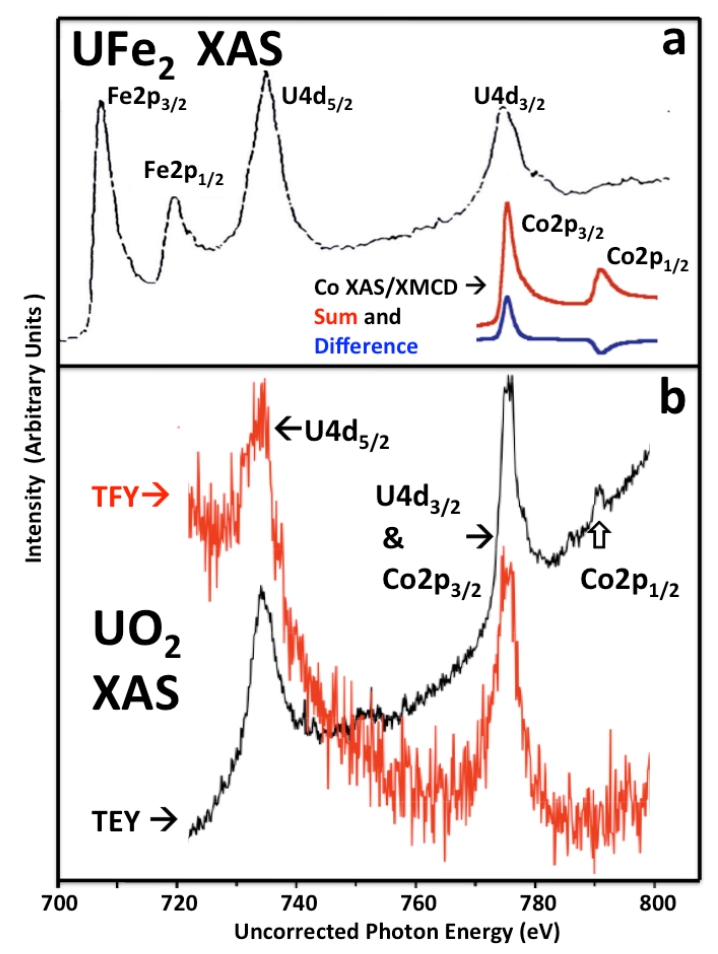

\section{Summary and Conclusions}

So, while theoretically possible, there are practical limitations that render this approach of having dubious potential for success. 


\section{Report on the Feasibility of Pu Photoelectron Spectroscopy with Microscopic and Nanoscopic Samples at NSLSII}

\section{References}

1. J.D. Denlinger et al, Rev. Sci. Instrum. 66, 1342 (1995).

2. H. Blumm et al, J. Elect. Spect. Relat. Phenom. 150, 86 (2006).

3. D. Price, J.S. Hildum and A.C. Williams, "Estimating Inventory Thresholds for Nuclear Facilities Using DOE STD-1027-92 Attachment 1 Table A.1 "Thresholds for Radionuclides," Safety Analysis Transitions Workshop Oakland, CA, June 9-13, 1997, UCRL-JC127245.

4. N.W. Ashcroft and N.D. Mermin, "Solid State Physics," Holt , Rinehart and Winston, New York, 1976.

5. J.G. Tobin et al, Phys. Rev. B 68, 155109 (2003); J. Terry et al, Surf. Sci. Letters 499, L141 (2002); J.G. Tobin et al, Phys. Rev. B 72, 085109 (2005); and references therein.

6. J.G. Tobin, "Soft x-ray and Vacuum Ultraviolet based Spectroscopy of the Actinides," $8^{\text {th }}$ School on the Physics and Chemistry of the Actinides, Stará Lesná, Slovakia, April 7 - 9, 2011

7. S.-W. Yu, J. G. Tobin, P. Olalde-Velasco, W. L. Yang, and W. J. Siekhaus, J. Vac. Sci. Tech. A. 30, 011402 (2012). 